\title{
Limitations of the ARDS criteria during high-flow oxygen or non-invasive ventilation: Evidence from critically ill COVID-19 patients
}

\author{
Michael Hultström ( $\square$ michael.hultstrom@mcb.uu.se ) \\ Uppsala Universitet https://orcid.org/0000-0003-4675-1099

\section{Ola Hellkvist}

Uppsala Universitet

\section{Lucian Covaciu}

Uppsala Universitet

Filip Fredén

Uppsala Universitet

\section{Robert Frithiof}

Uppsala Universitet

Miklós Lipcsey

Uppsala Universitet

\section{Gaetano Perchiazzi}

Uppsala Universitet

Mariangela Pellegrini

Uppsala Universitet

\section{Research Article}

Keywords: Acute respiratory distress syndrome, mechanical ventilation, high-flow oxygen, non-invasive ventilation

Posted Date: November 10th, 2021

DOI: https://doi.org/10.21203/rs.3.rs-1044681/v1

License: () (1) This work is licensed under a Creative Commons Attribution 4.0 International License. Read Full License

Version of Record: A version of this preprint was published at Critical Care on March 7th, 2022. See the published version at https://doi.org/10.1186/s13054-022-03933-1. 


\section{Abstract}

Introduction The ratio of partial pressure of arterial oxygen to inspired oxygen fraction (PaO2/FIO2) during invasive mechanical ventilation (MV) is used as criteria to grade the severity of respiratory failure in acute respiratory distress syndrome (ARDS). During the SARS-CoV2 pandemic the use of $\mathrm{PaO} / \mathrm{FIO} 2$ ratio has been increasingly used in non-invasive respiratory support such as high-flow nasal cannula (HFNC) and non-invasive ventilation (NIV). The grading of hypoxemia in non-invasively ventilated patients is uncertain. The main hypothesis, investigated in this study, was that the $\mathrm{PaO} 2 / \mathrm{FIO} 2$ ratio does not change when switching between MV, NIV and HFNC. Methods This was a sub-study of a single-center prospective observational study of patients admitted to the intensive care unit (ICU) at Uppsala University Hospital in Sweden for critical COVID-19. In a steady state condition, the PaO2/FIO2 ratio was recorded before and after any change between two of the studied respiratory support techniques (i.e., HFNC, NIV and MV). Results A total of 148 patients were included in the present analysis. We find that any change in respiratory support from or to HFNC caused a significant change in $\mathrm{PaO} 2 / \mathrm{FIO} 2$ ratio (up to $48 \mathrm{mmHg}$, from HFNC to MV). Changes in respiratory support between NIV and $\mathrm{MV}$ did not show consistent change in $\mathrm{PaO} / \mathrm{FIO} 2$ ratio. In patients classified as mild to moderate ARDS during $\mathrm{MV}$, the change from HFNC to MV showed a variable increase in PaO2/FIO2 ratio ranging between 52 and $140 \mathrm{mmHg}$ (median of $127 \mathrm{~mm} \mathrm{Hg}$ ). This made prediction of ARDS severity during MV from the apparent ARDS grade during HFNC impossible. Conclusion HFNC is associated with lower Pa02/FIO2 ratio than either NIV or MV in the same patient, while NIV and MV provided similar PaO2/FIO2 and thus ARDS grade by Berlin definition. The large variation of $\mathrm{PaO} 2 / \mathrm{FIO} 2$ ratio precludes using ARDS grade as a measure of pulmonary damage during HFNC.

\section{Introduction}

The Berlin definition of the acute respiratory distress syndrome (ARDS) [1] includes the ratio between the partial pressure of arterial oxygen and the fraction of inspired oxygen (the $\mathrm{PaO}_{2} / \mathrm{F}_{1} \mathrm{O}_{2}$ ratio) during invasive mechanical ventilation (MV) with a positive end-expiratory pressure (PEEP) higher than $5 \mathrm{~cm} \mathrm{H}_{2} \mathrm{O}$. This has been proven useful for research and clinical management of patients with acute respiratory failure as the degree of pulmonary damage, organ dysfunction and death in ARDS are closely associated with the severity of hypoxemia $[2,3]$.

During the last twenty years, we witnessed a growing interest in non-invasive respiratory support strategies for the treatment of acute hypoxemic respiratory failure [4]. This was further brought to the fore by the ongoing SARS-CoV2 pandemic, when an even wider use of high-flow nasal cannula oxygen therapy (HFNC) and noninvasive ventilation (NIV) was prompted by high demand for respiratory support [5]. While NIV provides a measurable PEEP that maybe consistent with the Berlin criteria, the level of PEEP generated by HFNC depends on multiple factors and cannot be reliably measured in the clinical setting $[6,7]$. Moreover, during non-invasive respiratory support, the actual inspiratory fraction of oxygen $\left(\mathrm{F}_{1} \mathrm{O}_{2}\right)$ is often uncertain because of leakage and variable dead space volume.

This means that the current ARDS criteria for grading hypoxemia are difficult or impossible to apply in noninvasively ventilated patients [8]. However, despite lacking clinical evidence, ARDS criteria have been applied to patients not undergoing invasive mechanical ventilation even though severity stratification may be inaccurate 
[9]. Moderate or severe hypoxemia during non-invasive respiratory support has been demonstrated to be an early predictor for need of invasive mechanical ventilation [10-12]. However, the uncertainties in the grading of hypoxemia in non-invasively ventilated patients jeopardizes the clinical decision process, and may negatively influence patient outcomes $[9,12-14]$.

The main aim of the current study was to allow the accurate stratification of respiratory dysfunction during HFNC and NIV in COVID-19 ARDS patients. To this end we investigated $\mathrm{PaO}_{2} / \mathrm{F}_{1} \mathrm{O}_{2}$ ratio and ROX index when changing respiratory support in patients affected by COVID-19 ARDS. The hypothesis was that $\mathrm{PaO}_{2} / \mathrm{F}_{1} \mathrm{O}_{2}$ ratio is altered by changing between MV, NIV and HFNC. Therefore, the Berlin criteria for ARDS should not be accurate for invasive as well as non-invasive respiratory support.

\section{Materials And Methods}

This was a sub-study of a single-center prospective observational cohort study including patients older than 18 years, positive to the PCR test for SARS-CoV2 on nasal swab specimen, and admitted to the ICU at Uppsala University Hospital in Sweden. All the included patients were admitted to the ICU for acute hypoxic respiratory failure and treated with one of the studied respiratory support methods (HFNC, NIV or MV) at admission. The inclusion period for this analysis was from the $14^{\text {th }}$ of March 2020 until the $14^{\text {th }}$ of January 2021. The National Ethical Review Agency approved the study (EPM; No. 2020-01623). The Declaration of Helsinki and its subsequent revisions were followed. The protocol was registered a priori (Clinical Trials ID: NCT04316884). STROBE guidelines were followed for reporting. Written informed consent was obtained from the patients when possible. Otherwise, informed consent was firstly asked to next to kin and later confirmed by patients if feasible.

\section{Laboratory, clinical and physiological variables}

In the current study we analyzed, in a steady state condition, the change in oxygenation in relation to a switch in respiratory support strategy between two of the following: HFNC, NIV and MV. For each included patient, the first two changes of respiratory support after admission to ICU were collected. The possible changes of respiratory support defined six comparisons: 1) HFNC-to-NIV; 2) HFNC-to-MV; 3) NIV-to-HFNC; 4) NIV-to-MV; 5) MV-to-HFNC; 6) MV-to-NIV.

To avoid collecting data during transient changes, the arterial blood gas analyses sampled after switching respiratory support were collected at least 30 minutes after the change, which we considered as steady-state changes. For each analyzed condition, the oxygenation was defined by the partial pressure of arterial oxygen and fraction of inspired oxygen $\left(\mathrm{PaO}_{2} / \mathrm{F}_{1} \mathrm{O}_{2}\right)$ ratio. Comprehensive clinical data about the included patients (e.g., demographics, chronic health conditions, vital signs, ventilatory settings and laboratory tests, including arterial blood gas analysis) were collected at ICU admission and as well as in conjunction with the changes in respiratory support. The $\mathrm{SpO}_{2}$ values were calculated based on measured $\mathrm{PO}_{2}$, based on the equation developed by Severinghaus [15]: $\mathrm{SO}_{2}=\left(\left(23400 *\left(\mathrm{PO}_{2}{ }^{3}+150 * \mathrm{PO}_{2}\right)^{-1}\right)+1\right)^{-1} * 100$. The list of the acquired clinical data was reported in Table 1. The ROX index [16] was calculated in the HFNC subgroups. The ROX index is defined as the ratio of pulse oximetry/fraction of inspired oxygen $\left(\mathrm{SpO}_{2} / \mathrm{F}_{1} \mathrm{O}_{2}\right)$ to respiratory rate (RR) per 
minute. A ROX index greater than or equal to 4.88 measured after 12 hours of HFNC has been shown to be associated with a low risk for invasive ventilation $[11,16]$.

\section{$\underline{\text { The } \mathrm{PaO}_{2}} \underline{\mathrm{F}_{\underline{1}}} \underline{\underline{\mathrm{O}}} \underline{\underline{\text { analysis }}}$}

The correlations between $\mathrm{PaO}_{2} / \mathrm{F}_{1} \mathrm{O}_{2}$ values, collected before and after a change in respiratory support, were tested. To compare the $\mathrm{PaO}_{2} / \mathrm{F}_{1} \mathrm{O}_{2}$ ratio during non-invasive respiratory support (HFNC or NIV) with the $\mathrm{PaO}_{2} / \mathrm{F}_{1} \mathrm{O}_{2}$ during $\mathrm{MV}$, the changes between HFNC and MV (in both directions: HFNC-to-MV and MV-to-HFNC) and the changes between NIV and MV (in both directions: NIV-to-MV and MV-to-NIV) were gathered together in a box plot and scatter plot analysis. The patients were divided in groups based on the Berlin criteria for ARDS during invasive ventilation [1]: 1) mild ARDS, with a $\mathrm{PaO}_{2} / \mathrm{F}_{1} \mathrm{O}_{2}$ between 201 and $300 \mathrm{mmHg}$; 2) moderate ARDS, with a $\mathrm{PaO}_{2} / \mathrm{F}_{1} \mathrm{O}_{2}$ between 101 and $200 \mathrm{mmHg} ; 3$ ) severe ARDS, $\mathrm{PaO}_{2} / \mathrm{F}_{1} \mathrm{O}_{2}$ lower than 100 $\mathrm{mmHg}$.

\section{$\underline{\text { Outcome }}$}

The primary outcome was the difference in $\mathrm{PaO}_{2} / \mathrm{F}_{1} \mathrm{O}_{2}$ ratio caused by a change of respiratory support modality.

\section{Statistical Analysis}

Data analysis and statistical tests were performed using dedicated MATLAB scripts (MATLAB and Statistics Toolbox Release 2020a, The MathWorks, Natick, USA). Quantitative variables were expressed as median (25 $5^{\text {th }}$ and $75^{\text {th }}$ percentiles - 25-75 - or interquartile range - IQR - if more appropriate), categorical variables were expressed as frequency (percentage).

The $\mathrm{PaO}_{2} / \mathrm{F}_{1} \mathrm{O}_{2}$ values, collected before and after a change in respiratory support, were scatter-plotted and described in relation with the diagonal to the axis. Correlation analysis (Pearson correlation) and a BlandAltman analysis [17] were performed on these paired data.

Continuous variables were compared using the two-sample Kolmogorov-Smirnov test $(a=0.05)$. In case of multiple comparisons, the Kruskal-Wallis test $(\alpha=0.05)$, followed by Bonferroni correction, was used. In order to use the Bland-Altman analysis, the Kolmogorov-Smirnov normality test was applied for testing normal distribution of differences between measurements.

\section{Results}

A total of 148 patients were included in the study. Two-hundred fifty-two changes of respiratory support were gathered and divided in the six subgroups as follow: 76 in HFNC-to-NIV, 34 in HFNC-to-MV; 59 in NIV-to-HFNC; 
36 in NIV-to-MV; 35 in MV-to-HFNC; 12 in MV-to-NIV. The median age of the included patients' population was 66 (55-73) years, 25\% were women (see Table 1 and supplementary Table 1). Patients' median body mass index was 29 (25.4-32.9) and $26 \%$ of the included patients had a previous diagnosis of chronic pulmonary disease. At ICU admission, almost all patients (141) had a motorial Glasgow coma scale of 5 or higher. The patients had a median simplified acute physiology score 3 of 53 (47-59) and a median of 10 days with respiratory symptoms before admission to the ICU. Patients' median $\mathrm{PaO}_{2} / \mathrm{F}_{1} \mathrm{O}_{2}$ ratio was $114 \mathrm{~mm} \mathrm{Hg}(101$ 148). Independently from the respiratory support used and from the actual PEEP, $26 \%$ of patients showed a moderate or severe ARDS $\left(\mathrm{PaO}_{2} / \mathrm{F}_{1} \mathrm{O}_{2}\right.$ equal to or lower than $\left.200 \mathrm{~mm} \mathrm{Hg}\right)$ at admission. The ROX index was significantly lower for HFNC patients who changed to MV (3.56) compared to those who continued on a noninvasive respiratory support (4.93). Compared to HFNC-to-NIV and HFNC-to-MV, changing of respiratory support in the opposite direction (NIV-to-HFNC and MV-to-HFNC) were characterized by a significantly higher ROX index (respectively 5.84 and 6.59) during HFNC.

\section{The $\mathrm{PaO}_{2} / \underline{\mathrm{F}}_{\underline{\underline{O}}} \underline{\underline{\mathrm{O}_{2}}} \underline{\text { analysis }}$}

Any change from or to HFNC showed a significant difference between the regression line and the diagonal to the axes. Moreover, compared to NIV-to-MV and MV-to-NIV, a lower $\mathrm{r}^{2}$ (correlation) and a higher difference between the delta in $\mathrm{PaO}_{2} / \mathrm{F}_{1} \mathrm{O}_{2}$ and the line of equality (Bland-Altman analysis) were shown (Figures $1 \mathrm{~A}-1 \mathrm{~F}$ and Tables 2A-2F).

On the other hand, changes in respiratory support between NIV and MV in both directions (NIV-to-MV and MV-toNIV) did not show significant differences in $\mathrm{PaO}_{2} / \mathrm{F}_{1} \mathrm{O}_{2}$ ratio (Figures $1 D$ and $1 F$, Tables $2 \mathrm{D}$ and $2 \mathrm{~F}$ and supplementary Table 2). This was consistent with a stronger regression for MV-to-NIV ( $r^{2}=0.65$ and the regression line slope of 0.74 , Figure $1 F$ and supplementary Table 2). These findings were confirmed by the Bland-Altman analysis where the differences in $\mathrm{PaO}_{2} / \mathrm{F}_{1} \mathrm{O}_{2}$ between NIV and $\mathrm{MV}$ in both directions did not significantly differ from the line of equality.

The $\mathrm{PaO}_{2} / \mathrm{F}_{1} \mathrm{O}_{2}$ ratio was analyzed based on ARDS severity during MV (Figures 2 and 3 and supplementary Figure 1). Patients that were classified in the severe ARDS group during MV showed the same level of severe hypoxemia during all kinds of respiratory support (Figure 2). In the mild ARDS group as well as in the moderate ARDS group, the median $\mathrm{PaO}_{2} / \mathrm{F}_{1} \mathrm{O}_{2}$ ratio was significantly higher during $\mathrm{MV}$ compared to $\mathrm{HFNC}$ or to NIV (Figure 2). Moreover, for those patients classified in the mild or moderate ARDS groups while mechanically ventilated, the variability of the $\mathrm{PaO}_{2} / \mathrm{F}_{1} \mathrm{O}_{2}$ ratio in $\mathrm{HFNC}$ or NIV was inversely related to the severity of the ARDS during MV. The lower the ARDS severity in MV, the higher the variability of $\mathrm{PaO}_{2} / \mathrm{F}_{1} \mathrm{O}_{2}$ values during HFNC or NIV. This variability was higher during HFNC compared to NIV (Figure 2). By a further subgroup analysis, dividing these patients in four groups: HFNC-to-MV, MV-to-HFNC, NIV-to-MV and MV-to-NIV (Figure 3 and supplementary Figures 1 ), the same findings could be confirmed. The widest $\mathrm{PaO}_{2} / \mathrm{F}_{1} \mathrm{O}_{2}$ variability was reported in mild ARDS and in the HFNC-to-MV group where the $\mathrm{PaO}_{2} / \mathrm{F}_{1} \mathrm{O}_{2}$ widely changed between 52 and $140 \mathrm{~mm} \mathrm{Hg}$, with a median value of $127 \mathrm{~mm} \mathrm{Hg}$.

\section{Discussion}


The primary finding of this study is the consistence of $\mathrm{PaO}_{2} / \mathrm{F}_{1} \mathrm{O}_{2}$ ratio between $\mathrm{MV}$ and NIV. However, a high variability in the effect on $\mathrm{PaO}_{2} / \mathrm{F}_{1} \mathrm{O}_{2}$ ratio was demonstrated when changing to or from HFNC. For instance, patients on HFNC with a $\mathrm{PaO}_{2} / \mathrm{F}_{1} \mathrm{O}_{2}$ of $100 \mathrm{~mm} \mathrm{Hg}$ could potentially change their $\mathrm{PaO}_{2} / \mathrm{F}_{1} \mathrm{O}_{2}$ ratio to all possible levels of ARDS severity after changing to MV (Figure 2).

Modern noninvasive forms of respiratory assistance, including NIV and HFNC, have been developed during the last thirty years, and their use has drastically increased during the SARS-CoV2 pandemic $[5,18]$. Therefore, the use of NIV and HFNC is not well described in clinical guidelines. Neither the ERS/ATS guidelines for acute respiratory failure [9], or the NIH recommendations for the respiratory management in critical COVID-19 patients [19] made any formal recommendation for non-invasive respiratory support. An unclear definition of the severity of hypoxemia in critically ill patients on non-invasive respiratory support can expose patients to the risk of a delayed initiation of invasive and controlled mechanical ventilation, worsening patients' outcomes [10,12,20]. The present findings provide a rationale for using $\mathrm{PaO}_{2} / \mathrm{F}_{1} \mathrm{O}_{2}$ during NIV for decisions related to intubation, but suggest great caution for its use during HFNC.

We showed that, the ability to oxygenate is not only determined by the severity of lung injury, but also by the respiratory support technique selected. The Berlin definition of ARDS was more reliable in critically ill COVID-19 ARDS patients treated with NIV than in patients treated with HFNC. HFNC gave a lower $\mathrm{PaO}_{2} / \mathrm{F}_{1} \mathrm{O}_{2}$ ratio than either NIV or MV in the same patient, while NIV and MV provided similar $\mathrm{PaO}_{2} / \mathrm{F}_{1} \mathrm{O}_{2}$ ratio and thus ARDS grade by Berlin definition. Furthermore, the large variability of $\mathrm{PaO}_{2} / \mathrm{F}_{1} \mathrm{O}_{2}$ changes all but precluded estimating ARDS grade as a measure of pulmonary damage during HFNC. An increase in $\mathrm{PaO}_{2} / \mathrm{F}_{1} \mathrm{O}_{2}$ ratio up to 127 (IQR 55) mm $\mathrm{Hg}$, with very large individual variations (between 52 and $140 \mathrm{~mm} \mathrm{Hg}$ ), was demonstrated when changing from HFNC to MV. Patients that during HFNC had a certain $\mathrm{PaO}_{2} / \mathrm{F}_{1} \mathrm{O}_{2}$ ratio could potentially show, during invasive mechanical ventilation, an ARDS severity that could widely vary from mild to severe.

Numerous indices have been suggested in literature to describe ARDS associated hypoxemia, $\mathrm{PaO} \mathrm{O}_{2} / \mathrm{F}_{1} \mathrm{O}_{2}$ ratio is widely used because of its simplicity [8]. In the current study we showed that, depending on different respiratory support strategies, clinicians may wrongly assume the severity of $A R D S$, if only based on $\mathrm{PaO}_{2} / \mathrm{F}_{1} \mathrm{O}_{2}$ values. It is well established that not only the respiratory strategies used, but also the respiratory settings [21] as well as the $\mathrm{F}_{1} \mathrm{O}_{2}$ delivered [22] influence the $\mathrm{PaO}_{2} / \mathrm{F}_{1} \mathrm{O}_{2}$ ratio. The nonlinearity between $\mathrm{PaO}_{2} / \mathrm{F}_{1} \mathrm{O}_{2}$ and $\mathrm{F}_{1} \mathrm{O}_{2}$ values is influenced by multiple factors, e.g., intrapulmonary shunt, arterio-venous difference of oxygen, partial pressure of arterial carbon dioxide, respiratory quotient and hemoglobin as well as the onset of absorption atelectasis [23]. Only a $\mathrm{F}_{1} \mathrm{O}_{2}$ of 1.0 eliminates the effects of ventilation/perfusion mismatch on the intrapulmonary shunt, but at the same time this induces absorption atelectasis and increases true shunt unless PEEP is applied [24]. The recognition of these physiological mechanisms as well as our results should prompt the use of more standardized procedures for grading hypoxemia and ARDS severity.

Our results confirmed the validity of the ROX index in predicting the need for invasive ventilation in patients treated on HFNC $[11,16]$. In the current study, the ROX index was significantly lower for HFNC patients who changed to MV (3.56) compared to those who continued on a non-invasive respiratory support (4.93). Although not yet recommended by any guidelines, the ROX index is likely to be a useful clinical tool. It is simple to 
monitor and characterized by a high positive predictive value in patients on HFNC in need of invasive mechanical ventilation [11]. The ROX index is likely to replace the $\mathrm{PaO}_{2} / \mathrm{F}_{1} \mathrm{O}_{2}$ ratio as $A R D S$ criteria in hypoxic patients on HFNC.

\section{Strengths and limitations}

This was the first study investigating the reliability of $\mathrm{PaO}_{2} / \mathrm{F}_{1} \mathrm{O}_{2}$ ratio in determining the severity of hypoxemia in COVID-19 ARDS patients. The large variation of the $\mathrm{PaO}_{2} / \mathrm{F}_{1} \mathrm{O}_{2}$ ratio during HFNC precluded using ARDS grade as a measure of pulmonary damage during HFNC.

The current study had some limitations. The study focused exclusively on $\mathrm{PaO}_{2} / \mathrm{F}_{1} \mathrm{O}_{2}$ ratio, not taking into account the complexity and the multifactorial nature of hypoxic acute respiratory failure and of its management as, for instance, the use of prone positioning, the level of sedation, muscle relaxation or other pharmaceutical interventions. However, when referring to the $\mathrm{PaO}_{2} / \mathrm{F}_{1} \mathrm{O}_{2}$ ratio in our clinical practice as well as in the Berlin definition of ARDS [1], the $\mathrm{PaO}_{2} / \mathrm{F}_{1} \mathrm{O}_{2}$ ratio is used as an independent variable, not contextualized to, for instance, patients' position, hemodynamic, muscle relaxation, sedation.

Being this a monocentric study, local clinical routines could have influence on the results.

The pathophysiological mechanisms leading to hypoxemia in COVID-19 ARDS can differ from the ones characterizing other kinds of acute hypoxic respiratory failure; consequently, the magnitude of changes in oxygenation indices described in this study is not surely generalizable to all kinds of ARDS. However, the current criteria for ARDS definition [1] does not distinguish among different pathophysiological mechanisms bringing to ARDS but characterized them through the same criteria.

\section{Conclusions}

$\mathrm{PaO}_{2} / \mathrm{F}_{1} \mathrm{O}_{2}$ ratio should not be used to grade hypoxemia in ARDS patients during HFNC. $\mathrm{PaO}_{2} / \mathrm{F}_{1} \mathrm{O}_{2}$ ratio during NIV is a reasonable estimate for actual ARDS grade during MV. There are large individual variations in the effect of changes in ventilatory modality that suggests future ARDS definitions should treat respiratory support strategies separately. Importantly, our findings indicate that clinical trials investigating non-invasive respiratory support in ARDS patients can lead to misinterpretation of patients' outcomes.

\section{Declarations}

\section{Ethics approval and consent to participate}

The National Ethical Review Agency approved the study (EPM; No. 2020-01623). The Declaration of Helsinki and its subsequent revisions were followed. Written informed consent was obtained from the patients when possible. Otherwise, informed consent was firstly asked to next to kin and later confirmed by patients if feasible. 


\section{Consent for publication}

Not applicable.

\section{Availability of data and material}

Data is available from the corresponding author on reasonable request

(https://doi.org/10.17044/scilifelab.14229410).

\section{Competing interest}

The authors declare that they have no conflicts of interest.

\section{Funding}

The study was funded by the SciLifeLab/Knut and Alice Wallenberg national COVID-19 research program (M.H.: KAW 2020.0182, KAW2020.0241), the Swedish Heart-Lung Foundation (M.H.: 20210089, 20190639, 20190637, and G.P.: 20200877 and 20200825), the Swedish Research Council (R.F.: 2014-02569, 2014-07606 and G.P.: 2018-02438). The Swedish Society for Medical Research (M.P. 463402221) and the Swedish Society of Medicine (M.P. SLS-959793) and Alvar Gullstrand research grant (G.P.: ALF-938050).

\section{Author contributions}

All authors participated in project design and planning. $\mathrm{MH}, \mathrm{OH}, \mathrm{RF}, \mathrm{ML}$ and $\mathrm{MP}$ collected data. MP and $\mathrm{MH}$ wrote the first draft. All authors revised the paper and approved the final version for publication.

\section{Acknowledgement}

The authors thank research nurses Joanna Wessbergh and Elin Söderman, and the biobank assistants Amanda Svensson, Labolina Spång, Erik Danielsson and Philip Karlsson for their expertise in compiling patient data.

\section{References}

1. Ranieri VM, Rubenfeld GD, Thompson BT, Ferguson ND, Caldwell E, Fan E, et al. Acute respiratory distress syndrome: the Berlin Definition. JAMA: the journal of the American Medical Association. 2012;307:2526-33. 
2. Bellani G, Laffey JG, Pham T, Fan E, Brochard L, Esteban A, et al. Epidemiology, Patterns of Care, and Mortality for Patients With Acute Respiratory Distress Syndrome in Intensive Care Units in 50 Countries. JAMA: the journal of the American Medical Association. 2016;315:788-800.

3. Martín-Rodríguez F, López-Izquierdo R, del Pozo Vegas C, Delgado-Benito J, Ortega G, Castro Villamor M, et al. Association of Prehospital Oxygen Saturation to Inspired Oxygen Ratio With 1-, 2-, and 7-Day Mortality. JAMA network open [Internet]. JAMA Netw Open; 2021 [cited 2021 Oct 1];4. Available from: https://pubmed-ncbi-nImnih-gov.ezproxy.its.uu.se/33847751/

4. Hill NS, Ruthazer R. Predicting outcomes of high-flow nasal cannula for acute respiratory distress syndrome. American Journal of Respiratory and Critical Care Medicine. American Thoracic Society; 2019;199:1300-2.

5. Ferguson ND, Pham T, Gong MN. How severe COVID-19 infection is changing ARDS management. Intensive Care Medicine [Internet]. 2020 [cited 2021 Jul 29];46:2184-6. Available from: https://doi.org/10.1007/s00134020-06245-6

6. Chertoff J. High-flow oxygen, positive end-expiratory pressure, and the Berlin definition of acute respiratory distress syndrome: Are they mutually exclusive? American Journal of Respiratory and Critical Care Medicine. 2017;196:396-7.

7. Spoletini G, Alotaibi M, Blasi F, Hill N. Heated Humidified High-Flow Nasal Oxygen in Adults: Mechanisms of Action and Clinical Implications. Chest. Chest; 2015;148:253-61.

8. Bellani G, Pham T, Laffey J. Missed or delayed diagnosis of ARDS: a common and serious problem. Intensive care medicine [Internet]. Intensive Care Med; 2020 [cited 2021 Oct 1];46:1180-3. Available from: https://pubmed-ncbi-nIm-nih-gov.ezproxy.its.uu.se/32328723/

9. Rochwerg B, Brochard L, Elliott MW, Hess D, Hill NS, Nava S, et al. Official ERS/ATS clinical practice guidelines: noninvasive ventilation for acute respiratory failure. European Respiratory Journal [Internet]. European Respiratory Society; 2017 [cited 2021 Jul 29];50:1602426. Available from:

https://erj.ersjournals.com/content/50/2/1602426

10. Antonelli M, Conti G, Moro M, Esquinas A, Gonzalez-Diaz G, Confalonieri M, et al. Predictors of failure of noninvasive positive pressure ventilation in patients with acute hypoxemic respiratory failure: a multi-center study. Intensive care medicine [Internet]. Intensive Care Med; 2001 [cited 2021 Jul 29];27:1718-28. Available from: https://pubmed-ncbi-nlm-nih-gov.ezproxy.its.uu.se/11810114/

11. Roca O, Caralt B, Messika J, Samper M, Sztrymf B, Hernández G, et al. An Index Combining Respiratory Rate and Oxygenation to Predict Outcome of Nasal High-Flow Therapy. American journal of respiratory and critical care medicine [Internet]. Am J Respir Crit Care Med; 2019 [cited 2021 Jul 29];199:1368-76. Available from: https://pubmed-ncbi-nlm-nih-gov.ezproxy.its.uu.se/30576221/

12. Kang B, Koh Y, Lim C, Huh J, Baek S, Han M, et al. Failure of high-flow nasal cannula therapy may delay intubation and increase mortality. Intensive care medicine [Internet]. Intensive Care Med; 2015 [cited 2021 Jul 29];41:623-32. Available from: https://pubmed-ncbi-nlm-nih-gov.ezproxy.its.uu.se/25691263/ 
13. Demoule A, Girou E, Richard J, Taille S, Brochard L. Benefits and risks of success or failure of noninvasive ventilation. Intensive care medicine [Internet]. Intensive Care Med; 2006 [cited 2021 Oct 1];32:1756-65. Available from: https://pubmed-ncbi-nlm-nih-gov.ezproxy.its.uu.se/17019559/

14. Ozyilmaz E, Ugurlu A, Nava S. Timing of noninvasive ventilation failure: causes, risk factors, and potential remedies. BMC pulmonary medicine [Internet]. BMC Pulm Med; 2014 [cited 2021 Oct 1];14. Available from: https://pubmed-ncbi-nlm-nih-gov.ezproxy.its.uu.se/24520952/

15. Severinghaus J. Simple, accurate equations for human blood 02 dissociation computations. Journal of applied physiology: respiratory, environmental and exercise physiology [Internet]. J Appl Physiol Respir Environ Exerc Physiol; 1979 [cited 2021 Oct 24];46:599-602. Available from: https://pubmed-ncbi-nlm-nihgov.ezproxy.its.uu.se/35496/

16. Roca O, Messika J, Caralt B, García-de-Acilu M, Sztrymf B, Ricard JD, et al. Predicting success of high-flow nasal cannula in pneumonia patients with hypoxemic respiratory failure: The utility of the ROX index. Journal of Critical Care. W.B. Saunders; 2016;35:200-5.

17. Bland J, Altman D. Measuring agreement in method comparison studies. Statistical methods in medical research [Internet]. Stat Methods Med Res; 1999 [cited 2021 Sep 30];8:135-60. Available from: https://pubmedncbi-nIm-nih-gov.ezproxy.its.uu.se/10501650/

18. Ricard J, Roca O, Lemiale V, Corley A, Braunlich J, Jones P, et al. Use of nasal high flow oxygen during acute respiratory failure. Intensive care medicine [Internet]. Intensive Care Med; 2020 [cited 2021 Oct 1];46:2238-47. Available from: https://pubmed-ncbi-nIm-nih-gov.ezproxy.its.uu.se/32901374/

19. COVID-19 Treatment Guidelines Panel. Coronavirus Disease 2019 (COVID-19) Treatment Guidelines. National Institutes of Health. Available at https://www.covid19treatmentguidelines.nih.gov. 2021.

20. Bellani G, Laffey J, Pham T, Madotto F, Fan E, L B, et al. Noninvasive Ventilation of Patients with Acute Respiratory Distress Syndrome. Insights from the LUNG SAFE Study. American journal of respiratory and critical care medicine [Internet]. Am J Respir Crit Care Med; 2017 [cited 2021 Jul 19];195:67-77. Available from: https://pubmed-ncbi-nIm-nih-gov.ezproxy.its.uu.se/27753501/

21. Ferguson N, Kacmarek R, Chiche J, Singh J, Hallett D, Mehta S, et al. Screening of ARDS patients using standardized ventilator settings: influence on enrollment in a clinical trial. Intensive care medicine [Internet]. Intensive Care Med; 2004 [cited 2021 Oct 5];30:1111-6. Available from: https://pubmed-ncbi-nlm-nihgov.ezproxy.its.uu.se/14991096/

22. Aboab J, Louis B, Jonson B, Brochard L. Relation between PaO2/FIO2 ratio and FIO2: a mathematical description. Intensive care medicine [Internet]. Intensive Care Med; 2006 [cited 2021 Oct 1];32:1494-7. Available from: https://pubmed-ncbi-nlm-nih-gov.ezproxy.its.uu.se/16896846/

23. Gowda M, Klocke R. Variability of indices of hypoxemia in adult respiratory distress syndrome. Critical care medicine [Internet]. Crit Care Med; 1997 [cited 2021 Oct 5];25:41-5. Available from: https://pubmed-ncbi-nlmnih-gov.ezproxy.its.uu.se/8989174/ 
24. Shapiro B, Cane R, Harrison R, Steiner M. Changes in intrapulmonary shunting with administration of 100 percent oxygen. Chest [Internet]. Chest; 1980 [cited 2021 Oct 5];77:138-41. Available from: https://pubmedncbi-nIm-nih-gov.ezproxy.its.uu.se/6986237/

\section{Tables}

Table 1. Descriptive statistics of all patients included in the study. Data were reported as median values $\left(25^{\text {th }}\right.$ and $75^{\text {th }}$ percentiles), mean (SD) or numerosity (\%). BMI: body mass index, GCS: Glasgow coma scale, SAPS 3 : the simplified acute physiology score $3, \mathrm{FIO}_{2}$ : inspiratory fraction of oxygen, $\mathrm{PaO}_{2}$ : partial pressure of arterial oxygen, $\mathrm{SpO}_{2}$ : peripheral oxygen saturation, ROX index: respiratory rate-oxygenation index, ARDS: acute respiratory distress syndrome.

Table 2. Respiratory parameters for each group before and after a change in ventilatory support. The six tested groups were: A: HFNC-to-NIV; B: HFNC-to-MV; C: NIV-to-HFNC; D: NIV-to-MV; E: MV-to-HFNC; F: MV-to-NIV. Data were reported as median values ( $25^{\text {th }}$ and $75^{\text {th }}$ perncetiles). $\mathrm{FIO}_{2}$ : inspiratory fraction of oxygen, $\mathrm{PaO}_{2}$ : partial pressure of arterial oxygen, $\mathrm{SpO}_{2}$ : peripheral oxygen saturation, $\mathrm{ROX}$ index: respiratory rate-oxygenation index, ARDS: acute respiratory distress syndrome.

\section{Table 1}




\begin{tabular}{|c|c|c|c|}
\hline & Median & $25^{\text {th }}$ & $75^{\text {th }}$ \\
\hline Age (years) & 66 & 55 & 73.0 \\
\hline Weight (kg) & 85.5 & 76 & 99.5 \\
\hline Length $(\mathrm{cm})$ & 175 & 168 & 181.0 \\
\hline BMI & 28.7 & 25.4 & 32.9 \\
\hline
\end{tabular}

Female

$\frac{\mathrm{n}}{36} \frac{\%}{25}$

Previous pulmonary disease

$\frac{\mathrm{n}}{38} \frac{\%}{26}$

GCS - Motor response (1--6) at patients' admission

$\begin{array}{ccc}\frac{\text { GCS -M6 }}{128} & & \text { GCS-M5 } \\ \frac{\text { GCS-M4 }_{1}}{} & \frac{\text { GCS -M1 }}{3}\end{array}$

Respiratory rate (bpm)

\begin{tabular}{ccccc} 
Median & & $25^{\text {th }}$ & & $75^{\text {th }}$ \\
\cline { 1 - 1 } 8 & & 23 & & 35 \\
89 & & 77 & & 98 \\
82 & & & 99
\end{tabular}

Body temperature

SAPS 3

COVID day at arrival

37.7

37.1

38.4

$\mathrm{FIO}_{2}$

53

10

47

59

$\mathrm{pH}$

$\mathrm{PaO}_{2}(\mathrm{~mm} \mathrm{Hg})$

$\mathrm{PaCO}_{2}(\mathrm{~mm} \mathrm{Hg})$

$\mathrm{PaO}_{2} / \mathrm{FIO}_{2}$ ratio $(\mathrm{mm} \mathrm{Hg})$

Base excess $(\mathrm{mmol} / \mathrm{L})$

$\mathrm{SpO}_{2}(\%)$

$\begin{array}{lll}60 & 50 & 70\end{array}$

7.46

7.43

7.48

$\begin{array}{lll}71 & 63 & 84\end{array}$

35

32

38

114

101

148

0.46

$-1.76$

1.79

93

89

95

ROX index

5.61

3.12

6.35 


\begin{tabular}{|c|c|c|}
\hline ARDS severity (Berlin definition) & $\mathrm{n}$ & $\%$ \\
\hline No-ARDS & 6 & 7 \\
\hline Mild & 14 & 67 \\
\hline Moderate & 136 & 23 \\
\hline \multirow[t]{2}{*}{ Severe } & 47 & 3 \\
\hline & $\mathrm{n}$ & $\%$ \\
\hline Vasoactive treatmet & 5 & 3 \\
\hline Antibiotic treatment & 85 & 59 \\
\hline
\end{tabular}

\section{Table 2A}


HFNC

\begin{tabular}{|c|c|c|c|}
\hline & Median & $25^{\text {th }}$ & $75^{\text {th }}$ \\
\hline $\begin{array}{l}\text { Respiratory } \\
\text { rate (bpm) }\end{array}$ & 29 & 25 & 38 \\
\hline $\mathrm{FIO}_{2}$ & 60 & 55 & 70 \\
\hline $\mathrm{pH}$ & 7.47 & 7.45 & 7.50 \\
\hline $\begin{array}{l}\mathrm{PaO}_{2}(\mathrm{~mm} \\
\mathrm{Hg})\end{array}$ & 64 & 59 & 73 \\
\hline $\begin{array}{l}\mathrm{PaCO}_{2} \\
(\mathrm{~mm} \mathrm{Hg})\end{array}$ & 35 & 31 & 38 \\
\hline $\begin{array}{l}\mathrm{PaO}_{2} / \mathrm{FIO}_{2} \\
\text { ratio (mm } \\
\mathrm{Hg})\end{array}$ & 102 & 89 & 129 \\
\hline $\begin{array}{l}\text { Base } \\
\text { excess } \\
(\mathrm{mmol} / \mathrm{L})\end{array}$ & 1.15 & -0.49 & 3.61 \\
\hline $\mathrm{SpO}_{2}(\%)$ & 92 & 90 & 94 \\
\hline ROX index & 4.93 & 3.8 & 6.18 \\
\hline $\begin{array}{l}\text { NIV - } \\
\text { HFNC }\end{array}$ & Median & $25^{\text {th }}$ & $75^{\text {th }}$ \\
\hline $\begin{array}{l}\text { Delta } \\
\mathrm{PaO}_{2} / \mathrm{FIO}_{2} \\
(\mathrm{~mm} \mathrm{Hg}))\end{array}$ & 29 & 15 & 60 \\
\hline
\end{tabular}

NIV

\begin{tabular}{|c|c|c|}
\hline Median & $25^{\text {th }}$ & $75^{\text {th }}$ \\
\hline 32 & 27 & 37 \\
\hline 57 & 50 & 65 \\
\hline
\end{tabular}

7.46

7.44

68

32

36

146

119

7.48

89

39

Two-sample KolmogorovSmirnov test $(\square=0.05)$

$0.04 *$

$0.03 *$

0.25

0.00

*

0.36

0.00

185

0.99

$\begin{array}{lll}0.91 & -0.68 & 3.01\end{array}$

$\begin{array}{lll}96 & 93 & 96\end{array}$

$0.00 *$

\section{ARDS}

severity

\begin{tabular}{|c|c|c|c|c|}
\hline (Berlin def) & Mild & Moderate & Mild & Moderate \\
\hline & 4 & 40 & 11 & 56 \\
\hline & Severe & No-ARDS & Severe & No-ARDS \\
\hline & 32 & 0 & 8 & 1 \\
\hline
\end{tabular}

\section{Table 2B}


HFNC

MV

Two-sample Kolmogorov-

\begin{tabular}{|c|c|c|c|c|c|c|c|c|}
\hline & Median & $25^{\text {th }}$ & $75^{\text {th }}$ & Median & $25^{\text {th }}$ & $75^{\text {th }}$ & \multicolumn{2}{|c|}{$\begin{array}{c}\text { Smirnov test } \\
(\square=0.05)\end{array}$} \\
\hline $\begin{array}{l}\text { Respiratory } \\
\text { rate (bpm) }\end{array}$ & 37 & 26 & 48 & 20 & 15 & 20 & 0.00 & $*$ \\
\hline $\mathrm{FIO}_{2}$ & 70 & 65 & 75 & 60 & 50 & 69 & 0.00 & $*$ \\
\hline $\mathrm{pH}$ & 7.46 & 7.45 & 7.48 & 7.41 & 7.37 & 7.44 & 0.00 & $*$ \\
\hline
\end{tabular}

$\mathrm{PaO}_{2}(\mathrm{~mm}$

$\mathrm{Hg})$
$\mathrm{PaCO}_{2}$

(mm Hg)

63

59

66

77

74

92

$0.00 *$

$\mathrm{PaO}_{2} / \mathrm{FIO}_{2}$

32

37

41

36

45

$0.00 *$

ratio $(\mathrm{mm}$

$\mathrm{Hg}$ )

86

80

99

136

115

162

0.00

Base

excess

$(\mathrm{mmol} / \mathrm{L})$

0.28

$-1.40$

2.37

0.19

1.86

2.28

0.95

$\mathrm{SpO}_{2}(\%)$

92

90

95

94

97

$0.00 *$

ROX index

3.56

2.69

4.67

MV - HFNC

Median

DV

$\mathrm{PaO}_{2} / \mathrm{FIO}_{2}$

( $\mathrm{mm} \mathrm{Hg}$ )

48

$25^{\text {th }}$

$75^{\text {th }}$

73

\section{ARDS}

severity

(Berlin def)

\begin{tabular}{|c|c|}
\hline Mild & Moderate \\
\hline 2 & 6 \\
\hline Severe & No-ARDS \\
\hline 2 & 0 \\
\hline
\end{tabular}

\begin{tabular}{|c|c|}
\hline Mild & Moderate \\
\hline 4 & 27 \\
\hline Severe & No-ARDS \\
\hline
\end{tabular}

Table 2C 
NIV

\begin{tabular}{|c|c|c|c|}
\hline & Median & $25^{\text {th }}$ & $75^{\text {th }}$ \\
\hline $\begin{array}{l}\text { Respiratory } \\
\text { rate (bpm) }\end{array}$ & 32 & 27 & 39 \\
\hline $\mathrm{FIO}_{2}$ & 49 & 40 & 55 \\
\hline $\mathrm{pH}$ & 7.46 & 7.43 & 7.48 \\
\hline $\begin{array}{l}\mathrm{PaO}_{2}(\mathrm{~mm} \\
\mathrm{Hg})\end{array}$ & 79 & 72 & 89 \\
\hline $\begin{array}{l}\mathrm{PaCO}_{2} \\
(\mathrm{~mm} \mathrm{Hg})\end{array}$ & 37 & 34 & 40 \\
\hline $\begin{array}{l}\text { ratio (mm } \\
\text { Hg) } \\
\text { Base }\end{array}$ & 167 & 153 & 198 \\
\hline $\begin{array}{l}\text { Base } \\
\text { excess } \\
(\mathrm{mmol} / \mathrm{L})\end{array}$ & 1.98 & 0.13 & 3.71 \\
\hline $\mathrm{SpO}_{2}(\%)$ & 96 & 94 & 97 \\
\hline ROX index & & & \\
\hline $\begin{array}{l}\text { HFNC - } \\
\text { NIV }\end{array}$ & Median & $25^{\text {th }}$ & $75^{\text {th }}$ \\
\hline $\begin{array}{l}\text { Delta } \\
\mathrm{PaO}_{2} / \mathrm{FIO}_{2} \\
(\mathrm{~mm} \mathrm{Hg}){ }^{2} \mathrm{Hg}\end{array}$ & -41 & -65 & -21 \\
\hline
\end{tabular}

4.74
HFNC

Two-sample KolmogorovSmirnov test $(\square=0.05)$

$0.00 *$

$0.00 *$

0.64

$\begin{array}{ll}7.45 & 7.49\end{array}$

$63 \quad 76$

$0.00 *$

69

35

32

38

0.31

120

109

150

$0.00 *$

1.60

$-0.74$

3.53

0.60

93

92

95

$0.00 *$

6.97

$\begin{array}{lll}5.84 & 4.74 & 6.97\end{array}$

ARDS severity (Berlin def)

\begin{tabular}{|c|c|c|c|}
\hline Mild & Moderate & Mild & Moderate \\
\hline 14 & 42 & 4 & 43 \\
\hline Severe & No-ARDS & Severe & No-ARDS \\
\hline 3 & 0 & 12 & 0 \\
\hline
\end{tabular}

Table 2D 
NIV

MV

\begin{tabular}{|c|c|c|c|c|c|c|c|c|}
\hline & Median & $25^{\text {th }}$ & $75^{\text {th }}$ & Median & $25^{\text {th }}$ & $75^{\text {th }}$ & $\begin{array}{c}\text { Smirnov } \\
(\square=0.05\end{array}$ & $\begin{array}{l}\text { test } \\
\text { 5) }\end{array}$ \\
\hline $\begin{array}{l}\text { Respiratory } \\
\text { rate (bpm) }\end{array}$ & 41 & 34 & 42 & 23 & 20 & 25 & 0.00 & * \\
\hline $\mathrm{FIO}_{2}$ & 64 & 60 & 70 & 70 & 60 & 80 & 0.42 & \\
\hline $\mathrm{pH}$ & 7.46 & 7.44 & 7.48 & 7.37 & 7.33 & 7.40 & 0.00 & * \\
\hline $\begin{array}{l}\mathrm{PaO}_{2}(\mathrm{~mm} \\
\mathrm{Hg})\end{array}$ & 66 & 60 & 74 & 72 & 66 & 89 & 0.04 & $*$ \\
\hline $\begin{array}{l}\mathrm{PaCO}_{2} \\
(\mathrm{~mm} \mathrm{Hg})\end{array}$ & 33 & 32 & 37 & 43 & 38 & 50 & 0.00 & * \\
\hline $\begin{array}{l}\mathrm{PaO}_{2} / \mathrm{FIO}_{2} \\
\text { ratio (mm } \\
\text { Hg) }\end{array}$ & 104 & 87 & 121 & 115 & 90 & 143 & 0.27 & \\
\hline $\begin{array}{l}\text { Base } \\
\text { excess } \\
(\mathrm{mmol} / \mathrm{L})\end{array}$ & -0.24 & -1.57 & 1.91 & -0.90 & -1.95 & 0.75 & 0.62 & \\
\hline $\mathrm{SpO}_{2}(\%)$ & 93 & 91 & 95 & 94 & 93 & 97 & & $*$ \\
\hline
\end{tabular}

\begin{tabular}{|c|c|c|c|}
\hline MV - NIV & Median & $25^{\text {th }}$ & $75^{\text {th }}$ \\
\hline $\begin{array}{l}\text { Delta } \\
\mathrm{PaO}_{2} / \mathrm{FIO}_{2}\end{array}$ & & & \\
\hline$(\mathrm{mm} \mathrm{Hg})$ & 11 & -7.5 & 38 \\
\hline
\end{tabular}

\section{ARDS}

severity

\begin{tabular}{|c|c|c|c|c|}
\hline (Berlin def) & Mild & Moderate & Mild & Moderate \\
\hline & 0 & 20 & 2 & 20 \\
\hline & Severe & No-ARDS & Severe & No-ARDS \\
\hline & 16 & 0 & 14 & 0 \\
\hline
\end{tabular}

Table 2E 


\begin{tabular}{|c|c|c|c|c|c|c|c|c|}
\hline & Median & $25^{\text {th }}$ & $75^{\text {th }}$ & Median & $25^{\text {th }}$ & $75^{\text {th }}$ & $\begin{array}{r}\text { Smirnov } \\
(\square=0.0\end{array}$ & $\begin{array}{l}\text { test } \\
5 \text { ) }\end{array}$ \\
\hline $\begin{array}{l}\text { Respiratory } \\
\text { rate (bpm) }\end{array}$ & 26 & 20 & 33 & 27 & 25 & 37 & 0.14 & \\
\hline $\mathrm{FIO}_{2}$ & 35 & 30 & 40 & 50 & 40 & 52 & 0.00 & $*$ \\
\hline $\mathrm{pH}$ & 7.46 & 7.43 & 7.47 & 7.45 & 7.43 & 7.48 & 0.66 & \\
\hline $\begin{array}{l}\mathrm{PaO}_{2}(\mathrm{~mm} \\
\mathrm{Hg})\end{array}$ & 73 & 68 & 81 & 74 & 68 & 83 & 0.96 & \\
\hline $\begin{array}{l}\mathrm{PaCO}_{2} \\
(\mathrm{~mm} \mathrm{Hg})\end{array}$ & 40 & 38 & 42 & 39 & 35 & 42 & 0.60 & \\
\hline $\begin{array}{l}\mathrm{PaO}_{2} / \mathrm{FIO}_{2} \\
\text { ratio (mm } \\
\mathrm{Hg})\end{array}$ & 203 & 176 & 235 & 155 & 128 & 192 & 0.00 & $*$ \\
\hline $\begin{array}{l}\text { Base } \\
\text { excess } \\
(\mathrm{mmol} / \mathrm{L})\end{array}$ & 2.94 & 2.04 & 4.41 & 2.98 & 0.59 & 4.43 & 0.96 & \\
\hline $\mathrm{SpO}_{2}(\%)$ & 94 & 93 & 96 & 95 & 93 & 96 & 0.96 & \\
\hline ROX index & & & & 6.59 & 4.94 & 8.33 & & \\
\hline
\end{tabular}

\begin{tabular}{|c|c|c|c|}
\hline HFNC - MV & Median & $25^{\text {th }}$ & $75^{\text {th }}$ \\
\hline $\begin{array}{l}\text { Delta } \\
\mathrm{PaO}_{2} / \mathrm{FIO}_{2}\end{array}$ & & & \\
\hline (mm Hg) & -45 & -58 & -26 \\
\hline
\end{tabular}

\section{ARDS}

severity

\begin{tabular}{|c|c|c|c|c|}
\hline \multirow{2}{*}{ (Berlin def) } & Mild & Moderate & Mild & Moderate \\
\hline & 17 & 15 & 7 & 26 \\
\hline & Severe & No-ARDS & Severe & No-ARDS \\
\hline & 1 & 2 & 1 & 1 \\
\hline
\end{tabular}

Table 2F 
MV

NIV

Median

Respiratory

rate $(\mathrm{bpm})$

$\mathrm{FIO}_{2}$

$\mathrm{pH}$

$\mathrm{PaO}_{2}(\mathrm{~mm}$

$\mathrm{Hg})$

$\mathrm{PaCO}_{2}$

( $\mathrm{mm} \mathrm{Hg}$ )

$\mathrm{PaO}_{2} / \mathrm{FIO}_{2}$

ratio $(\mathrm{mm}$

$\mathrm{Hg}$ )

Base

excess

$(\mathrm{mmol} / \mathrm{L})$

$\mathrm{SpO}_{2}(\%)$

27.5

40

7.44

75

39

174

0.85

$-0.43$

66

35

140

197

20

0.12

2.89

31

45

7.41

74

5
94

93

95

95

34

139

$-0.49$

94

$75^{\text {th }}$

NIV - MV

Median

$\mathrm{PaO}_{2} / \mathrm{FIO}_{2}$

(mm Hg)

$-4$

$25^{\mathrm{th}}$

$75^{\text {th }}$

$-23$

8

\section{ARDS}

severity

(Berlin def)

\begin{tabular}{|c|c|}
\hline Mild & Moderate \\
\hline 3 & 9 \\
\hline Severe & No-ARDS \\
\hline 0 & 0 \\
\hline
\end{tabular}

\begin{tabular}{|c|c|}
\hline Mild & Moderate \\
\hline 2 & 10 \\
\hline Severe & No-ARDS \\
\hline
\end{tabular}

Figures 
A

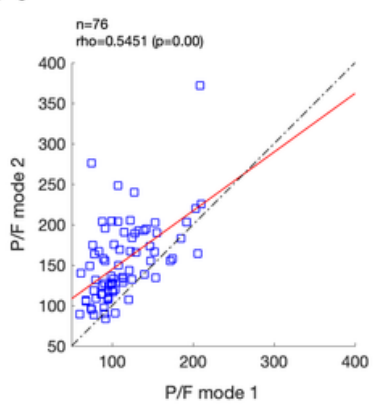

C

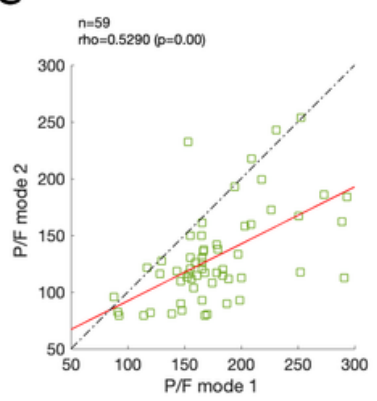

E

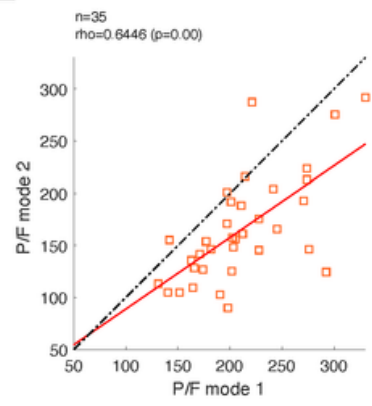

HFNC to NIV

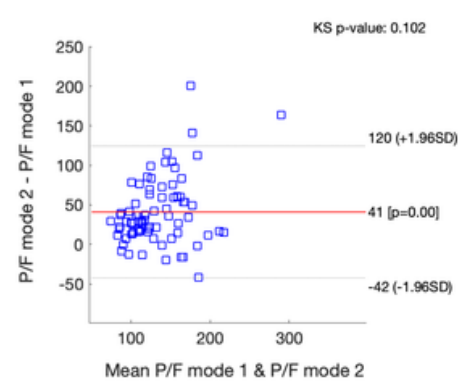

NIV to HFNC

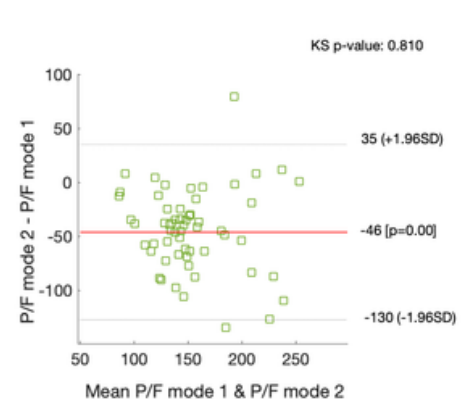

momem

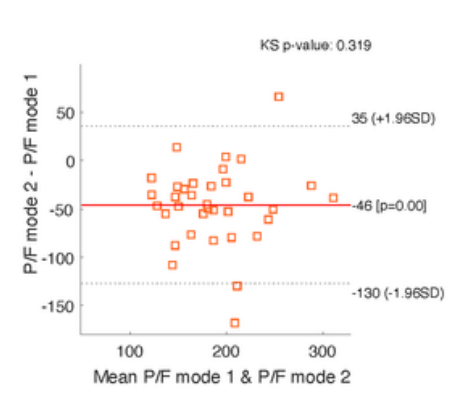

B

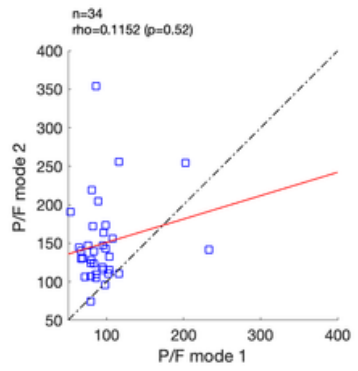

NIV to MV

D

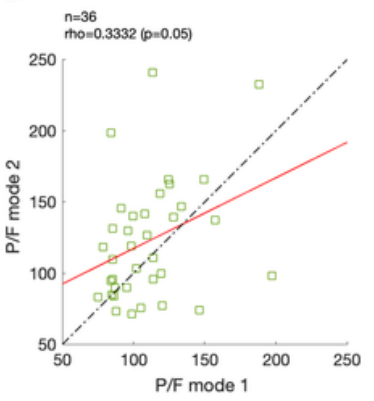

F

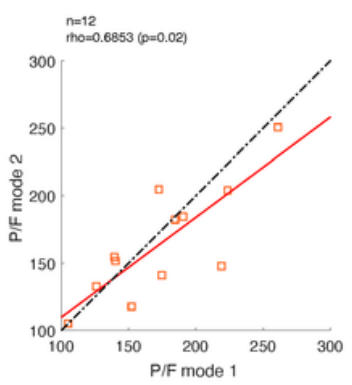

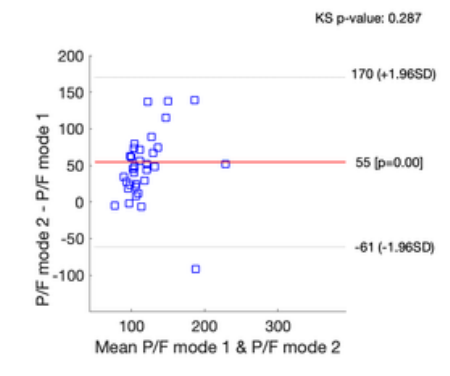

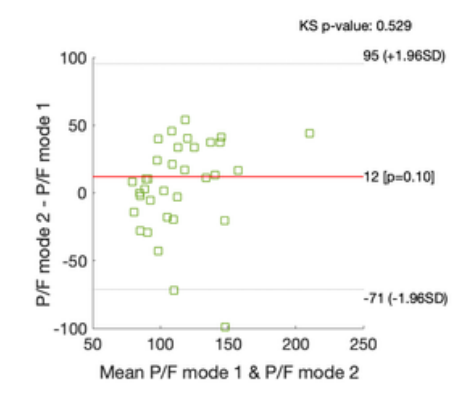

HFNC to MV

IV to NN

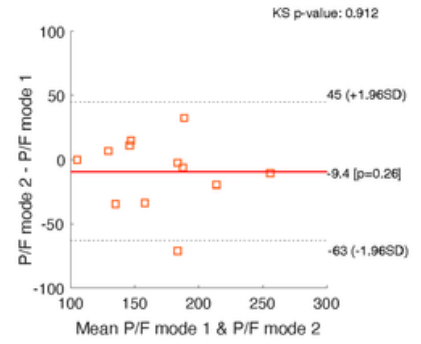

Figure 1

$\mathrm{PaO2/FIO2} \mathrm{ratio} \mathrm{before} \mathrm{and} \mathrm{after} \mathrm{a} \mathrm{change} \mathrm{in} \mathrm{ventilatory} \mathrm{support.} \mathrm{The} \mathrm{six} \mathrm{tested} \mathrm{groups} \mathrm{were:} \mathrm{A:} \mathrm{HFNC-to-NIV;} \mathrm{B:}$ HFNC-to-MV; C: NIV-to-HFNC; D: NIV-to-MV; E: MV-to-HFNC; F: MV-to-NIV. Analysis performed: Pearson correlation and a Bland-Altman analysis for $\mathrm{PaO} 2 / \mathrm{FIO} 2$ ratio (left) and ROX index (right). Descriptive statistics for the studied group (below). FIO2: inspiratory fraction of oxygen, PaO2: partial pressure of arterial oxygen, Sp02: peripheral oxygen saturation, ROX index: respiratory rate-oxygenation index, ARDS: acute respiratory distress syndrome. 
A

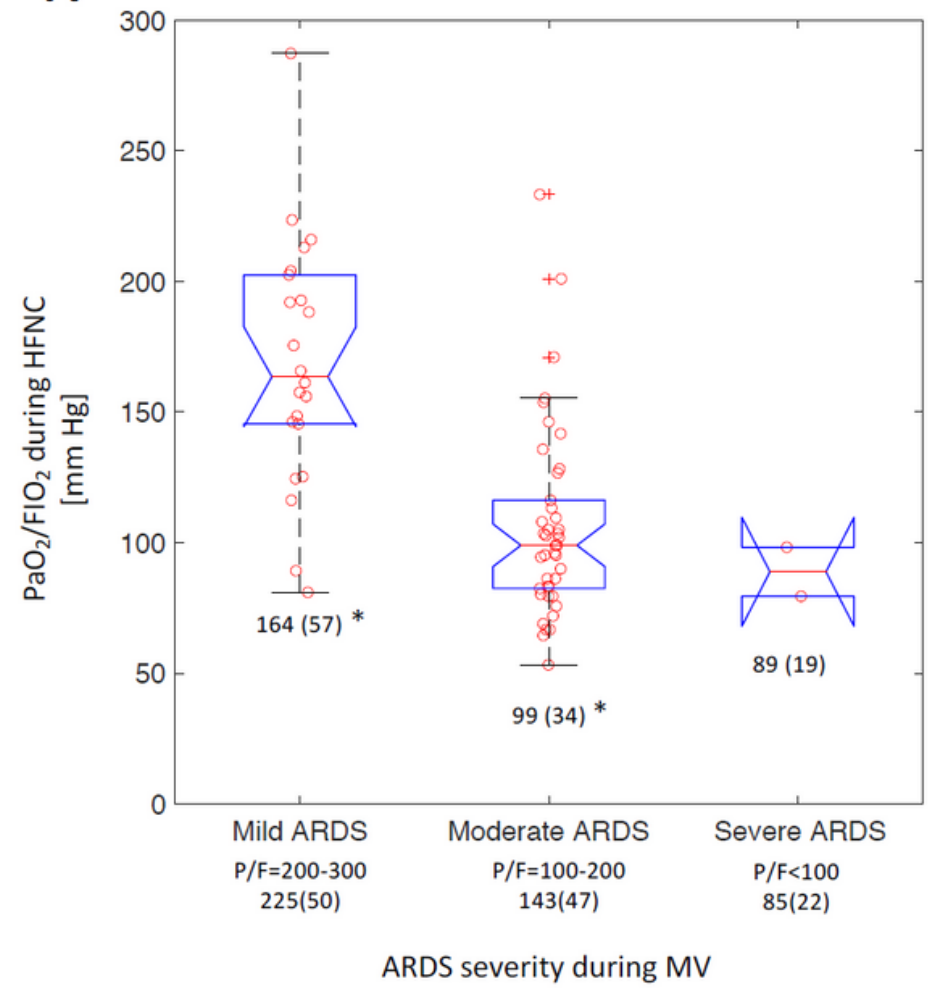

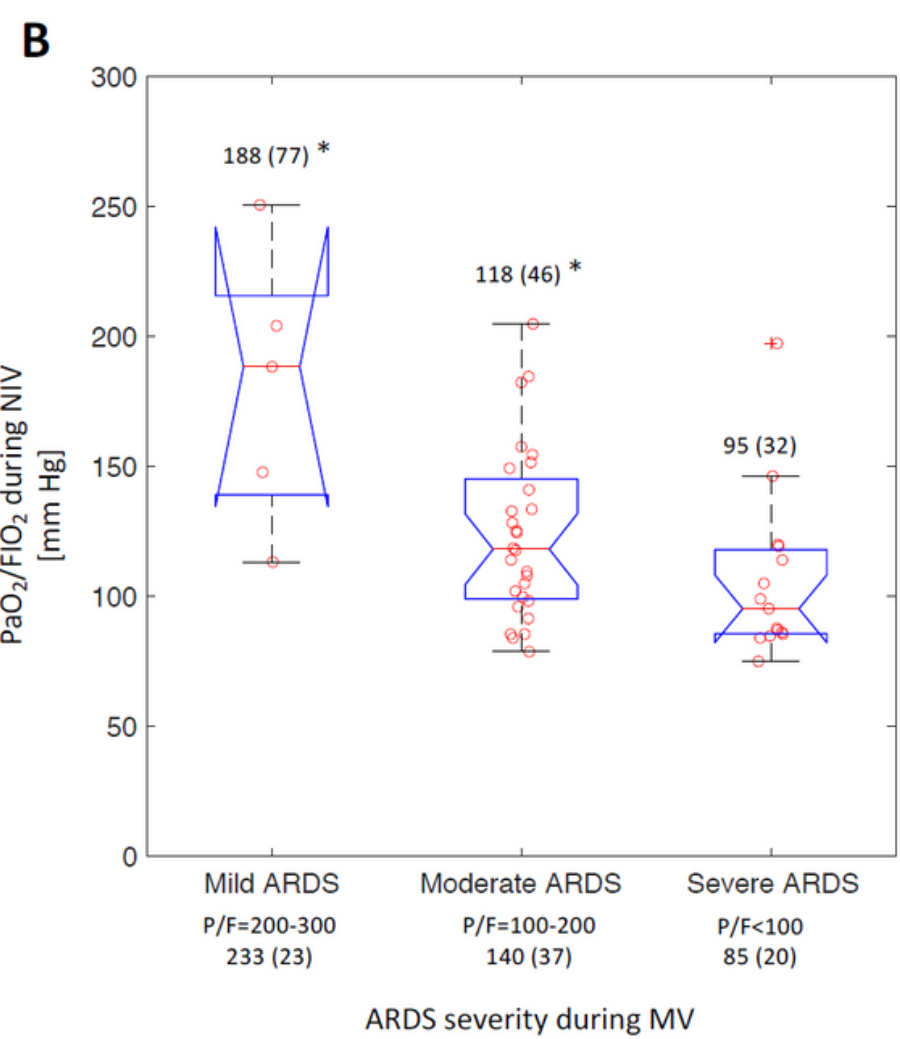

Figure 2

P02/FIO2 ratio during HFNC (A) and NIV (B) grouped by ARDS severity during mechanical ventilation (MV) based on the Berlin definition. A shows data from the two subgroups HFNC-to-MV and MV-to-HFNC. B shows data from the two subgroups NIV-to-MV and MV-to-NIV. Two-sample Kolmogorov-Smirnov test $(\alpha=0.05)$ was used to test statistical differences between ventilatory conditions. + : to indicate outliers, red line to indicate median values. * : to indicate statistical differences between HFNC (or NIV) and MV. 

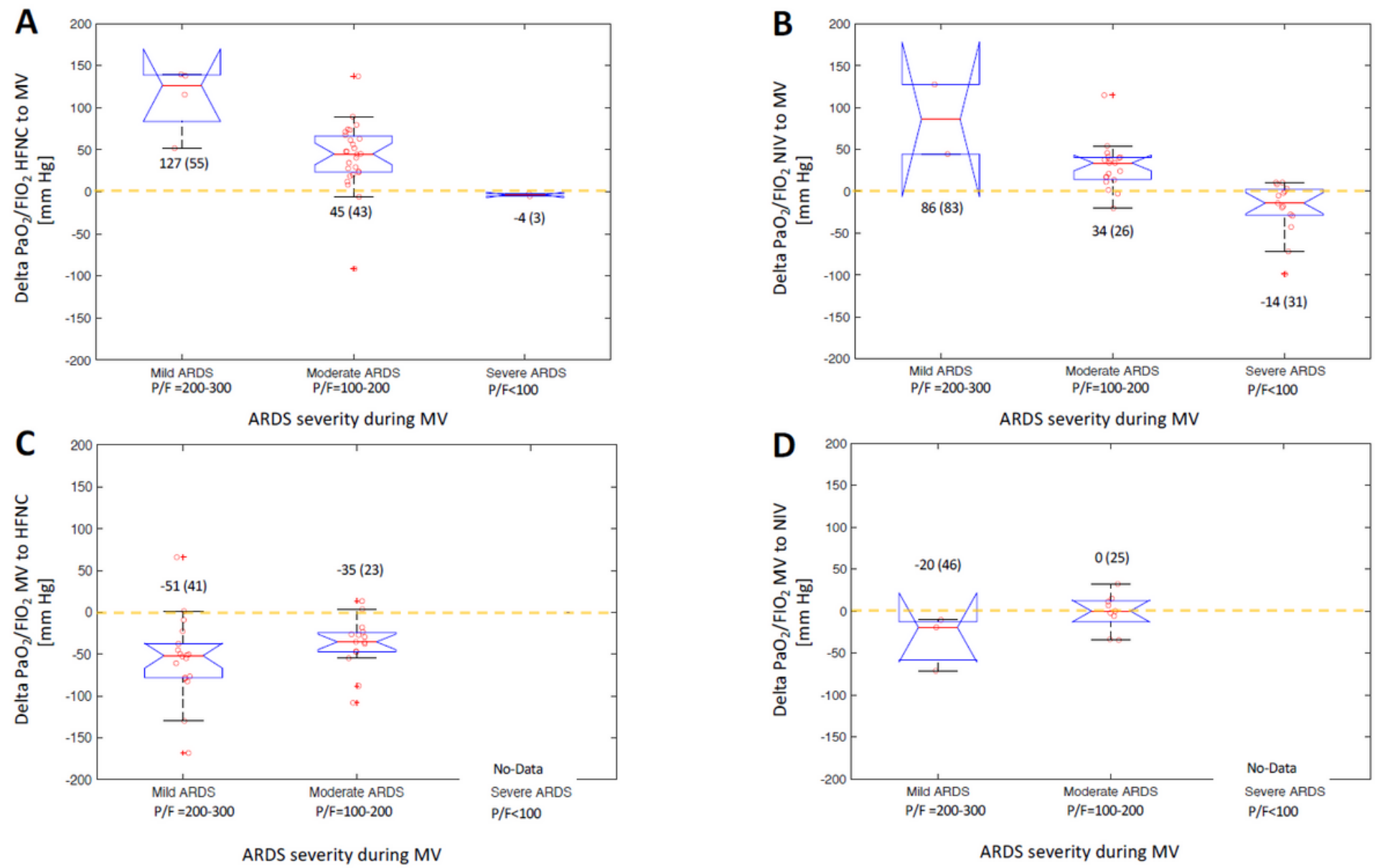

\section{Figure 3}

Change in P02/FIO2 after a change in respiratory support grouped by ARDS severity during mechanical ventilation (MV) based on the Berlin definition. A: HFNC to MV. B: NIV to MV. C: MV to HFNC. D: MV to NIV.

\section{Supplementary Files}

This is a list of supplementary files associated with this preprint. Click to download.

- SupplementARDSBerlinoxygenationcriteria20211031MH.docx 